\title{
Controlling the Defects of Paint Shop using Seven Quality Control Tools in an Automotive Factory
}

\author{
Imdad Ali Memon \\ Department of Mechanical Engineering \\ Quaid-e-Awam University of \\ Engineering, Science \& Technology \\ Nawabshah, Pakistan \\ engineerimdad@yahoo.com
}

Umair Ahmed Rajput

Department of Mechanical Engineering Quaid-e-Awam University of Engineering, Science \& Technology

Nawabshah, Pakistan engr.umair@quest.edu.pk

\author{
Ahmed Ali \\ Department of Electrical Engineering \\ Sukkur IBA University \\ Sukkur, Pakistan \\ ahmed.shah@iba-suk.edu.pk
}

\author{
Saeed Ahmed Khan Abro \\ Department of Electrical Engineering \\ Sukkur IBA University \\ Sukkur, Pakistan \\ saeed.abro@iba-suk.edu.pk
}

\author{
Munawar Ayaz Memon \\ Department of Electrical Engineering \\ Quaid-e-Awam University of \\ Engineering, Science \& Technology \\ Nawabshah, Pakistan \\ engr.mam@gmail.com \\ Ahsan Ali Memon \\ Department of Mechanical Engineering \\ Quaid-e-Awam University of \\ Engineering, Science \& Technology \\ Nawabshah, Pakistan \\ 15el06@quest.edu.pk
}

\begin{abstract}
Seven quality control (7QC) tools are used for reducing defects during manufacturing. These tools are highly effective in productivity and quality improvement. In this case, the study of the 7QC tools was applied in an automotive factory in order to reduce paint shop defects. Within four months the production line was inspected, defects were categorized and the 7QC tools were successfully applied, reducing the overall defect rate by $70 \%$. Although every tool was important, the cause and effect diagram was responsible for finding the root causes of the defects.
\end{abstract}

Keywords-defects reduction; productivity improvement; paint shop; 7QC tools

\section{INTRODUCTION}

The Seven Quality Control (7QC) tools are highly useful for improving productivity, resolving problems in the quality operational process and delivery $[1,2]$. The $7 \mathrm{QC}$ tools are applied for improving the performance of the production processes, solving problems at any stage [3, 4]. Solving problems by the 7QC tools reduces cost, while they cannot be replaced by any other complex decision-making support system [5]. The level of defects or problems in the product is associated with the process conditions. If the process is under control limit then the product is useful, while when the process is out of control the product has demerits resulting to rejection, rework or scrap [6]. These problem solving tools are directly beneficial for customers too, as quality products entail the vast reduction of defects, while this process reduces cost. Improving the quality of the product is very important for any company and its endurance in the market. The 7QC tools can be used in the production processing line ensuring the reduction of defects while suggesting improvements [7]. Statistical Process Control (SPC) tools used to hold the position of 7QC tools. These tools have played an important role in the reduction of variations in Corresponding author: Imdad Ali Memon many industries [8]. Many studies focused on these tools which were found very effective regarding problem solving in many industries. A comparative study was conducted between them and the new 7QC tools [8]. It has been reported that there are more than two SPC techniques, namely the Ishikawa diagram (cause and effect diagram) and the SPC control charts which were also applied in automotive industry. The study in [9] focused on the defects in shocker seals of the automotive industry. The rejection level was reduced from $9.1 \%$ to $5 \%$ and $95 \%$ process capability was achieved. The control chart alone was applied to automotive components and monitored process capability. It was reported that the defect level has been reduced using a data acquisition system. The automated inspection method was adopted and offline SPC method was converted into the online method in [10]. In many companies, more complex quality tools were used, but they were not highly effective and also they were not able to examine defects at a proper level [11].

In today's challenging environment, every organization should apply proper productivity improvement tools. This paper presents a case study of the application of the 7QC tools in an automotive factory. Initially, the factory used partially some of the tools without getting fruitful results. A goal to apply all the 7QC tools and understand their implementation mechanism was set, focusing on the identification and reduction of the defects occurring in the paint shop. An inspection point of the paint shop was used in order to collect, assess and analyze data.

\section{RELATED WORK}

The 7QC tools are applicable to any kind of industry regardless of size and capacity $[11,12]$. These techniques (flow chart, Pareto diagram, check sheet, control chart, histogram, 
scatter plot, cause-and-effect diagram) aim to control quality parameters such as methods, machine, equipment, and products. Hence, these tools reduce the loss and give more profit [13]. In [7], the 7QC tools were used for reducing the rejection of shift fork. The total rejection was reduced from $16.66 \%$ to $0.65 \%$, saving Rs 303.000 per year. In [14] the cost impact of the application of real time SPC in hardwood sawmills was investigated. In [15], some of the basic statistical tools were selected, such as Pareto diagram, control chart and histogram, studying their impact on the overall process performance, cost and product quality. In [16], the importance of the 7QC tools was examined, showing a continuous quality improvement process in an automotive industry, while in [17] those tools were used for productivity improvement. Many companies adopted SPC tools and continued the implementation of process control in manufacturing industries. These techniques fulfill the customer requirements for highquality products at low price. Manufacturing firms use SPC to analyze their impact, isolate problems, monitor the outcome and process parameters for achieving quality goals [18, 19]. Moreover, the SPC process can enhance problem solving and performance $[9,20]$.

Paint is a dispersion of pigments. It is used as filler in a fluid vehicle. The fluid vehicle includes a liquid binder that was solidified during cure. It has the capability to serve as a liquid carrier, viscosity reducing aid, and also provide healthy application distinctive [21]. Drying oil, volatile thinner, and paint have been developed by mixing, grinding, thinning, straining operations [22]

\section{MATERIALS AND METHODS}

Data collection started from the assessment of the automotive factory, through frequent visits. After visual inspection, defects were categorized in four types: dust, floatation, scratch, and improper paint. Then, defects having a direct impact on the car body were focused. Therefore, a check sheet was developed for finding the root cause of paint defects, applying the cause and effect diagram technique. This technique is very useful for the reduction of body section defects $[23,24]$. Data were collected through the check sheet for four months, using the same pattern. These data can be simulated, as reported in [25].

\section{RESULTS AND DISCUSSION}

\section{A. Application of the 7QC Tools}

- Flow chart (QC Tool 1): It was developed for collecting data from the paint shop. The defects observed at paint shop are of four types: scratch, dust, improper paint and floatation.

- Check sheets (QC tool 2): After identifying the defects, the next step is data collection. The check sheets were developed for collecting defect data for further analysis, and were designed focusing on attributted data, providing simple checkmarks, where check inspectors marked defect occurences. The check sheets mentioned different types of defects in the paint shop. Data were collected from November 2015 to February 2016.
- Histograms (QC tool 3): Histograms were created using Excel. The histograms display variation levels and process capability. Occurrence frequency of each defect was displayed in a monthly histogram between November 2015 to February 2016, as shown in Figure 1.

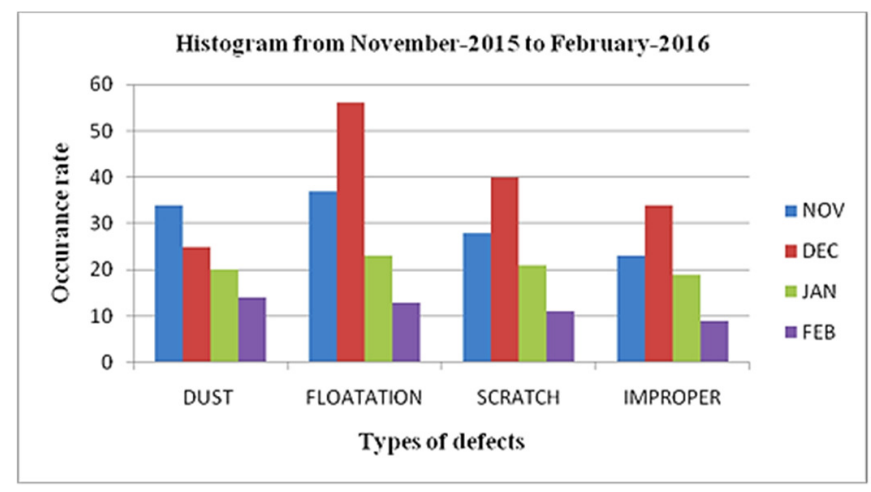

Fig. 1. Histogram for paint shop defects

- Pareto diagrams (QC tool 4): A Pareto diagram shows the defects in descending order of occurrences. The Pareto diagram is also monitoring the defects cumulative frequency level occurrences on its secondary axis. The red trend line shows the defect cumulative percentage level. Defects occurring at a high level should be given priority. The Pareto diagrams are displayed in Figure 2.

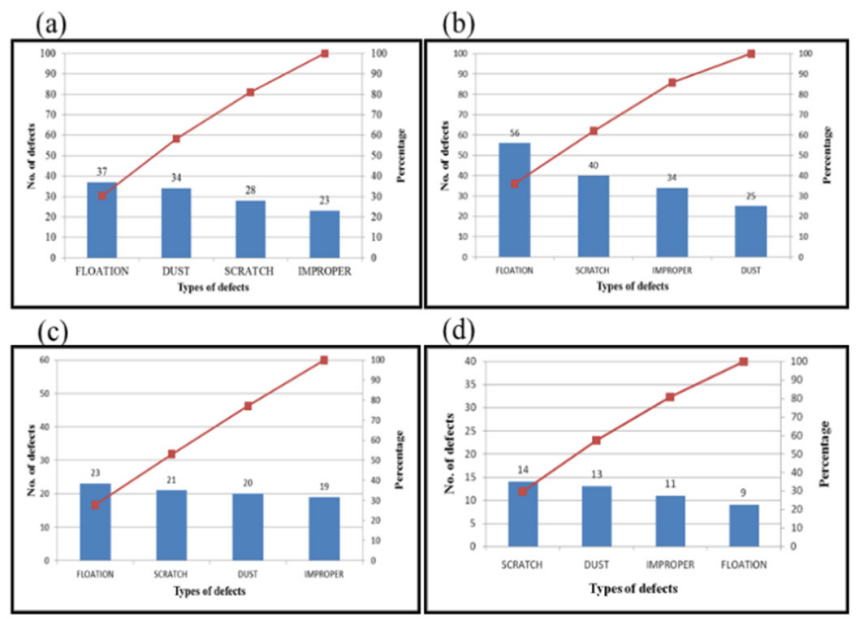

Fig. 2. Pareto charts of paint shop defects for (a) Nov-15, (b) Dec-15, (c) Jan-16 and (d) Feb-16

- Cause and effect diagram (QC Tool 5): The cause and effect diagram helps in discovering the root causes of the problem. This tool can point out the defects and their reasons. The preliminary data collected through check sheets showed a high frequency of defects in November and December 2015. Cause and effect diagrams were developed and applied in the paint shop. Using check sheets the data were collected for January 2016 and February 2016, 
showing considerable reduction in paint defects, due to control on root causes as pointed out in Figure 3.

- Scatter diagram (QC tool 6): This tool was used for the study and evaluation of the impact of each parameter to another. Fig. 4 shows the scatter diagram of the paint shop. This diagram shows time in weeks and the number of defective bodies. In the first eight weeks, the defect rate was too high, while after finding the root cause of defects through cause and effect diagram, it was observed that the occurrence rate of defective bodies was reduced.

(a)

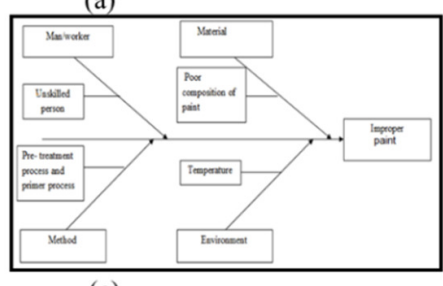

(c)

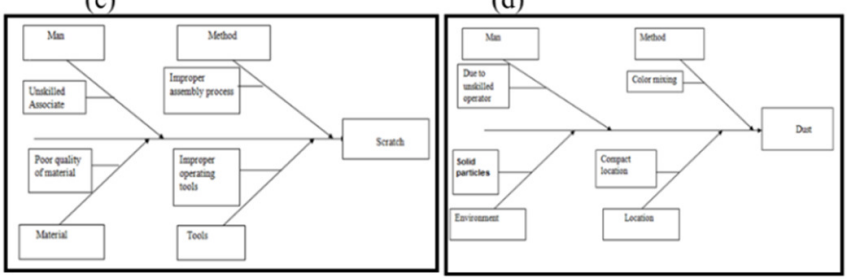

Fig. 3. Cause and effect diagram for paint shop of: (a) improper paint, (b) floatation, (c) scratch, and (d) dust

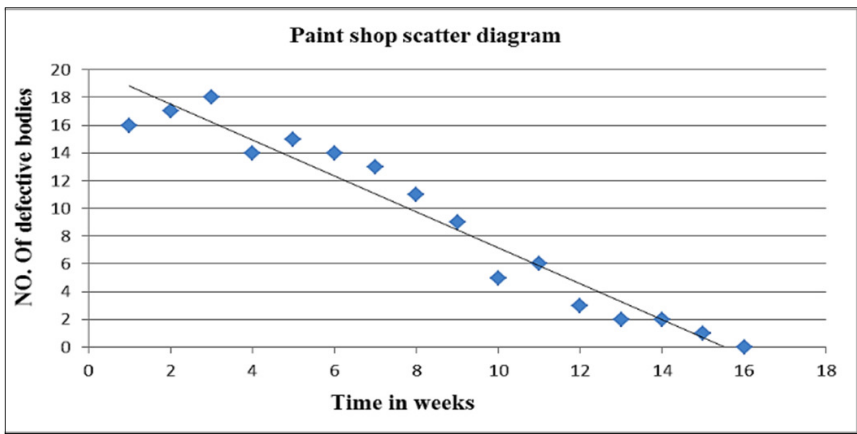

Fig. 4. Scatter diagram

- $\quad \mathrm{p}$-chart (QC tool 7): The p-chart was based on the number of paint defect occurrences using binominal distribution. The process, running either in statistical control or not, can be pointed by the P-chart. It also pointed out that the changes occurred in the defective items when process measurement took place.

\section{B. Overall Defect Reduction}

Figure 5 shows the NP control chart for the paint shop, where the blue line shows the defect rate, the green line shows the upper control limit, the red line shows the center and the purple line shows the lower control limit. Nine weeks after the implementation of the 7QC tools, the defections were drastically reduced. Figure 6 shows the impact on the defect rate before and after the implementation of $7 \mathrm{QC}$ tools in the paint shop. 122 defects occurred during the first month and 155 occurred during the second. After using the 7QC tools the defects were reduced to 83 during the third month and to 47 during the fourth.

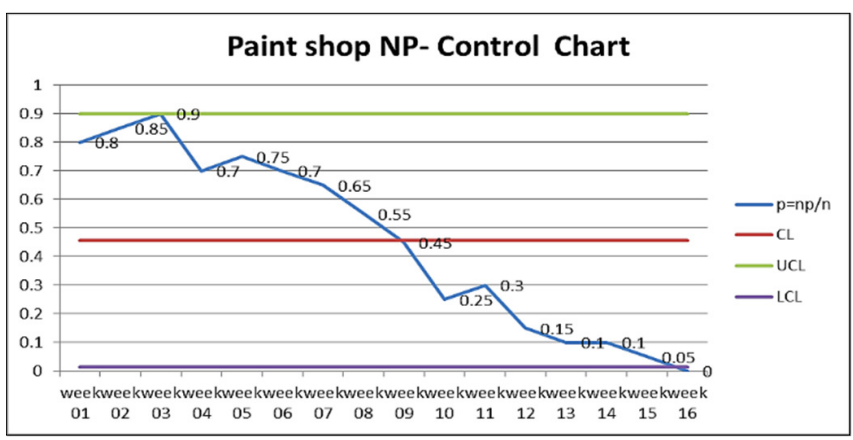

Fig. 5. NP control chart

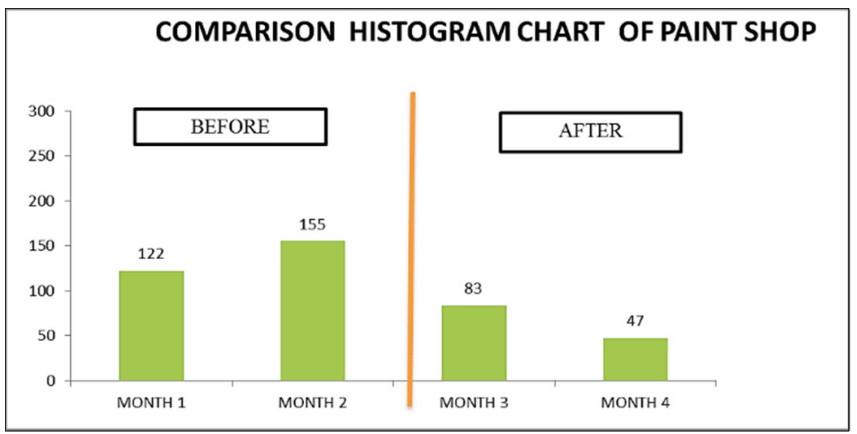

Fig. 6. Reduction of defects after the application of the 7QC tools

\section{CONCLUSION}

This research investigated the application of the 7QC tools for the reduction of defects it an automotive factory. The initial flow chart was developed and check sheets were designed for data collection on inspection points. It was observed that the highest frequency defects were seen in November and December, 2015. After using the cause and effect diagram, the defects reduced substantially. During the fourth month (February 2016) total defects reduced by $70 \%$, comparing to the first month, from 155 to 47. Every tool played an important role in the defect reduction, but the cause and effect diagram was very useful for finding the cause and its effect. The main contribution of this study is to highlight all the possible defects or errors affecting production in manufacturing industries.

\section{REFERENCES}

[1] J. C. Benneyan, "The design, selection, and performance of statistical control charts for healthcare process improvement". International Journal of Six Sigma and Competitive Advantage, Vol. 4, No. 3, p. 209239, 2008

[2] P. Kuendee, "Application of 7 quality control (7 QC) tools for quality management: A case study of a liquid chemical warehousing", 4th International Conference on Industrial Engineering and Applications, Nagoya, Japan, April 21-23, 2017

[3] H. Hailu, H. Tabuchi, H. Ezawa, K. Jilcha, "Reduction of excessive trimming and reject leather by integration of $7 \mathrm{QC}$ tools and QC story formula: The case report of Sheba Leather PLC", Industrial Engineering \& Management, Vol. 6, No. 3, 2017 
[4] B. Neyestani, "Seven basic tools of quality control: The appropriate techniques for solving quality problems in the organizations", SSRN, available at: https://zenodo.org/record/400832\#.XdPBdJMzaUl, 2017

[5] N. Visveshwar, V. Vishal, V. Venkatesh, R. V. Samsingh, P. Karthik, "Application of quality tools in a plastic based production industry to achieve the continuous improvement cycle", Calitatea, Vol. 18, No. 157, pp. 61-64, 2017

[6] P. S. Parmar, T. N. Desai, "Reduction of rework cost in manufacturing industry using statistical process control techniques: a case study", Industrial Engineering Journal, Vol. 10, No. 6, pp. 40-46, 2017

[7] A. Jaware, K. Bhandare, G. Sonawane, S. Bhagat, R. Ralebhat, "Reduction of machining rejection of shift fork by using seven quality tools", International Journal of Engineering and Technology, Vol. 5, No. 4, pp. 4323-4334, 2018

[8] S. M. Ahmed, R. T. Aoieong, S. L. Tang, D. X. Zheng, "A comparison of quality management systems in the construction industries of Hong Kong and the USA", International Journal of Quality \& Reliability Management, Vol. 22, No. 2, pp. 149-161, 2005

[9] D. R. Prajapati, "Implementation of SPC techniques in automotive industry: a case study", International Journal of Emerging Technology and Advanced Engineering, Vol. 2, No. 3, pp. 227-241, 2012

[10] T. V. U. K. Kumar, "SPC tools in automobile component to analyze inspection process", Vol. 2, No. 1, pp. 624-630, 2013

[11] C. Fotopoulos, E. Psomas, "The use of quality management tools and techniques in ISO 9001:2000 certified companies: The Greek case", International Journal of Productivity and Performance Management, Vol. 58, No. 6, pp. 564-580, 2009

[12] R. H. Fouad, A. Mukattash, "Statistical process control tools : a practical guide for Jordanian Industrial Organizations", Vol. 4, No. 6, pp. 693700, 2010

[13] R. Srinivasu, G. S. Reddy, S. R. Rikkula, "Utility of quality control tools and statistical process control to improve the productivity and quality in an industry", International Journal of Reviews in Computing, Vol. 5, pp. 15-20, 2011

[14] T. M. Young, B. H. Bond, J. Wiedenbeck, "Implementation of a realtime statistical process control system in hardwood sawmills", Forest Products Journal, Vol. 57, No. 9, pp. 54-62, 2007

[15] N. Afzaal, A. Aftab, S. Khan, M. Najamuddin, "To analyze the use of statistical tools for cost effectiveness and quality of products", IOSR Journal of Humanities and Social Science, Vol. 20, No. 1, pp. 47-57, 2015

[16] G. Paliska, D. Pavletic, M. Sokovic, "Quality tools: systematic use in process industry", Journal of Achievements in Materials and Manufacturing Engineering, Vol. 25, No. 1, pp. 79-82, 2007

[17] M. Sokovic, J. Jovanovic, J. Krivokapic, A. Vujovic, "Basic quality tools in continuous improvement process", Journal of Mechanical Engineering, Vol. 55, No. 5 pp. 333-341, 2009

[18] G. Patidar, D. D. S. Verma, "Implimantation of statistical process control in small scale industries- a review", International Journal of Technologies and Engineering, Vol. 2, No. 7, pp. 121-124, 2015

[19] V. Parkash, D. Kumar, R. Rajoria, "Statistical process control", International Journal of Research in Engineering and Technology, Vol. 2, No. 8, pp. 70-72, 2013

[20] P. S. Parmar, V. A. Deshpande, "Implementation of statistical process control techniques in industry: a review", Journal of Emerging Technologies and Innovative Research, Vol. 1, No. 6, pp. 583-587, 2014

[21] J. V. Koleske, "Mechanical properties of solid coatings", in: Encyclopedia of Analytical Chemistry: Applications, Theory and Instrumentation, John Wiley and Sons, 2006

[22] A. E. Bryson, The control of quality in the manufacture of paint, $\mathrm{PhD}$ Thesis, Masachusetts Institute of Technology, 1950

[23] P. Bhangale, R. Dhake, G. Gambhire, "Reduction in defects of car body panel using 7QC tools approach", National Conference on Modelling, Optimization and Control, Pune, India, March 4-6, 2015

[24] I. A. Memon, Q. B. Jamali, A. S. Jamali, M. K. Abbasi, N. A. Jamali, Z. H. Jamali, "Defect reduction with the use of seven quality control tools for productivity improvement at an automobile company", Engineering,
Technology and Applied Science Research, Vol. 9, No. 2, pp. 4044 4047, 2019

[25] M. L. Chew Hernandez, L. Viveros Rosas, R. F. Retes Mantilla, G. Espinosa Martínez, V. Velazquez Romero, "Supply chain cooperation by agreed reduction of behavior variability: a simulation-based study", Engineering, Technology and Applied Science Research, Vol. 7, No. 2, pp. 1546-1551, 2016 